\title{
P7170, a novel inhibitor of mTORC1/mTORC2 and Activin receptor-like Kinase 1 (ALK1) inhibits the growth of non small cell lung cancer
}

Venkatasubbaiah A Venkatesha, Asavari Joshi, Magesh Venkataraman, Vinay Sonawane, Dimple Bhatia, Prashant Tannu, Julie Bose, Sarika Choudhari, Ankita Srivastava, Prashant Kumar Pandey, Vaibhavi J Lad, Ramachandra Sangana, Tausif Ahmed, Anagha Damre, Vijaykumar Deore, Bichismita Sahu, Sanjay Kumar, Somesh Sharma and Veena R Agarwal ${ }^{*}$

\begin{abstract}
Background: Lung cancer is the major cause of cancer-related deaths and many cases of Non Small Cell Lung Cancer (NSCLC), a common type of lung cancer, have frequent genetic/oncogenic activation of EGFR, KRAS, PIK3CA, $B R A F$, and others that drive tumor growth. Some patients though initially respond, but later develop resistance to erlotinib/gefitinib with no option except for cytotoxic therapy. Therefore, development of novel targeted therapeutics is imperative to provide improved survival benefit for NSCLC patients. The mTOR cell survival pathway is activated in naive, or in response to targeted therapies in NSCLC.

Methods: We have discovered P7170, a small molecule inhibitor of mTORC1/mTORC2/ALK1 and investigated its antitumor efficacy using various in vitro and in vivo models of human NSCLC.

Results: P7170 inhibited the phosphorylation of AKT, S6 and 4EBP1 (substrates for mTORC2 and mTORC1) levels by 80-100\% and growth of NSCLC cells. P7170 inhibited anchorage-independent colony formation of NSCLC patient tumor-derived cells subsistent of disease sub-types. The compound also induced apoptosis in NSCLC cell lines. P7170 at a well-tolerated daily dose of $20 \mathrm{mg} / \mathrm{kg}$ significantly inhibited the growth of NSCLC xenografts independent of different mutations (EGFR, KRAS, or PIK3CA) or sensitivity to erlotinib. Pharmacokinetic-pharmacodynamic (PK-PD) analysis showed sub-micro molar tumor concentrations along with mTORC1/C2 inhibition.
\end{abstract}

Conclusions: Our results provide evidence of antitumor activity of P7170 in the erlotinib-sensitive and -insensitive models of NSCLC.

Keywords: NSCLC, mTORC1, mTORC2, STAT3, PI3K, EGFR-TKI, Tumor xenograft, Targeted therapeutics, PK-PD

\section{Background}

Lung cancer remains the leading cause of cancer related deaths worldwide. Eighty-five percent of the lung cancer cases are presented as Non-Small Cell Lung Cancers (NSCLC) in contrast to fifteen percent of Small Cell Lung Cancers (SCLC), and typically seventy-five percent of NSCLC new cases are being diagnosed at late advanced disease stage (ACS, Surveillance Research, 2013; [1]). Current research suggests that the importance of several molecular signaling pathways in Non-Small

\footnotetext{
* Correspondence: veena_828@yahoo.com

Piramal Life Sciences Ltd. \# 1 Nirlon Complex, Off: Western Express Highway, Goregaon (East), Mumbai, Maharashtra 400063, India
}

Cell Lung Cancer (NSCLC) cells that promote tumor growth. These include, but are not limited to activating mutations or amplification of EGFR, KRAS, PIK3CA, $B R A F$, and $E M L 4-A L K$ gene rearrangements and loss of PTEN [2-4].

The frequencies of activating mutations of EGFR and/ or KRAS in NSCLC varied in different studies $(8-60 \%)$ depending on the patient selection biases [5-7]. Recently, in a large and unselected cohort prospective screening of newly diagnosed 552 NSCLC patients, the EGFR mutation rate was found to be only $4.9 \%$ [8]. Despite an improved PFS (progression free survival) with EGFRTKI (tyrosine kinase inhibitor) that effectively targets 
mutant EGFR avidly than wild type, the overall survival remained controversial $[9,10]$. These findings suggest a possible role of other molecular pathways in the NSCLC disease progression. A retrospective study of patients showed that KRAS mutation with or without EGFR copy number alteration could predict chances of NSCLC disease progression [11]. Blocking RAS-RAF-MEK-ERK cell growth pathway that channelizes signals from upstream EGFR, KRAS, and BRAF [12-14] has been shown to be important in treating NSCLC. In addition, constitutive activation of AKT has emerged as a mechanism of cell survival and/or resistance to chemotherapy and radiation in NSCLC [15]. Utilization of ErbB-3 signaling in response to gefitinib in gefitinib-sensitive cells and IGFIR signaling in gefitinib-resistant cells was shown as a compensatory mechanisms that result in the activation of phosphoinositide 3-kinase (PI3K) in EGFR wild type NSCLC cells $[16,17]$. Also, cooperative up regulation of PI3K and mammalian Target Of Rapamycin (mTOR) pathways in NSCLC patient specimens with or no EGFR mutations suggested the importance of PI3K-mTOR signaling in NSCLC [18-20]. Additionally, suppression of PI3K-mTOR pathway has shown to be effective in inhibiting the growth of KRAS mutant NSCLC tumors in a mouse model [21]. Hyper activation of mTOR signaling frequently occurs in nearly $70 \%$ of patient tumors and because mTOR regulate eukaryotic cellular functions such as cell growth, cell survival, metabolism, response to stress, translation, and transcription through multiple pathways [22], several mTOR inhibitors are being discovered and evaluated for cancer therapy. It is now understood that both mTORC1 and mTORC2 activity is essential for growth of a subset of tumors by activating 4EBP1/ribosomal S6 and AKT respectively, hence an inhibitor for the same remain needed. Therefore, we developed an mTOR pathway inhibitor P7170 that showed potent inhibitory activity on mTORC1, mTORC2, and ALK1. [A separate manuscript under revision in the journal, Molecular Cancer Therapeutics; AACR 2012 conference posters: Agarwal VR et al., Can Res, 2012, 72(8 Supplement): Abstract no 3742 and 3759]. In this report we provide evidence for its efficacy in patient tumor-derived lung cancer cells in vitro and in mouse models of erlotinib-sensitive and -insensitive NSCLC cell line-derived xenografts. The chemical structure of P7170 is included in the patent \# WO-2012007926A1.

\section{Results}

\section{P7170 inhibited mTOR signaling}

We evaluated the activity of P7170 in cell based assays. The phosphorylation of AKT (S473) (substrate of mTORC2) [23], S6 (indirect substrate of mTORC1), and 4EBP1 (substrate of mTORC1) were nearly completely inhibited (100\%) in H460 NSCLC cells upon treatment with $50 \mathrm{nM}$ P7170. In the same experiment, phosphorylation of ERK, the effector of RAF-MEK-ERK pathway was marginally decreased (10\%) (Figure 1A). The kinase activities of upstream PI3K alpha and mTOR were inhibited by P7170 $\left(\mathrm{IC}_{50}=2.2\right.$ and $4.4 \mathrm{nM}$, respectively) but potent biochemical activity of PI3K did not translate in intact cells most likely because of feedback mechanism of mTOR inhibition. P7170 is a weak PI3K inhibitor (a separate manuscript submitted). In an immunofluorescence assay, P7170 treatment caused a consistent and marked decrease in the phosphorylation of S6 with a concentration-dependent suppression of p4EBP1 in H460 cells (Figure 1B, Additional file 1: Figure S1). Longer incubation time with P7170 resulted in an enhanced inhibition of pS6 and p4EBP1 (Additional file 1: Figure S1). The effect of P7170 on cell growth was evaluated in three different NSCLC cell lines, where a dose-dependent inhibition was observed. The $\mathrm{IC}_{50}$ of P7170 in EGFR over expressing A431 (EGFR wild type) cells was $10 \mathrm{nM}$ compared to 5 and $7 \mathrm{nM}$ in KRAS mutant A549 and H460 cell lines, respectively. In general, P7170 showed nano molar $\mathrm{IC}_{50}$ concentrations in the growth of various NSCLC cell lines as opposed to micro molar $\mathrm{IC}_{50}$ of erlotinib (Figure $1 \mathrm{C}$ ).

\section{P7170 inhibited the clonogenic potential of patient tumor derived cancer cells}

Tumor specimens used in this study were histologically derived from three sub-types e.g., adenocarcinoma (FA), squamous cell carcinoma (FE), or large cell carcinoma (FL) where, the tumor cells derived from human xenografts were designated with a prefix 'LX' (Table 1). Although the mutation status of EGFR or other key genes in these patient tumor-derived cells is unknown, the status of KRAS, PIK3CA, or PTEN was mostly wild type (Table 1). To examine the effect of P7170 on the clonogenic activity, tumor cells obtained from 13 different lung cancer patient biopsies were treated with P7170 (0.01 nM-1 $\mu \mathrm{M})$ followed by monitoring their growth in soft-agar. The concentration that resulted in the $50 \%$ attenuation of colony formation $\left(\mathrm{IC}_{50}\right)$ of P7170 was computed as described in Table 1 and Additional file 2: Figure S2. The $\mathrm{IC}_{50}$ values for P7170 were in the broad range of 3 to $300 \mathrm{nM}$ independent of either the genetic status of KRAS, PIK3CA, PTEN or the tumor sub-types (Table 1).

\section{P7170 caused apoptosis and STAT3 inhibition in cancer cell lines}

To further understand the mechanism of cell growth inhibition, H460 cells were treated with P7170 for $24 \mathrm{~h}$ and analyzed by flow cytometry for propidium positive dead cells. A significant increase in dead cells upon treatment with P7170 was observed at $10 \mathrm{nM}$ compared to untreated control $(\mathrm{p}<0.05$; Figure $2 \mathrm{~A})$. In the Annexin $\mathrm{V}$-propidium iodide apoptosis assay, we found that treatment with $300 \mathrm{nM}$ P7170 resulted in a 35\% loss of cell 


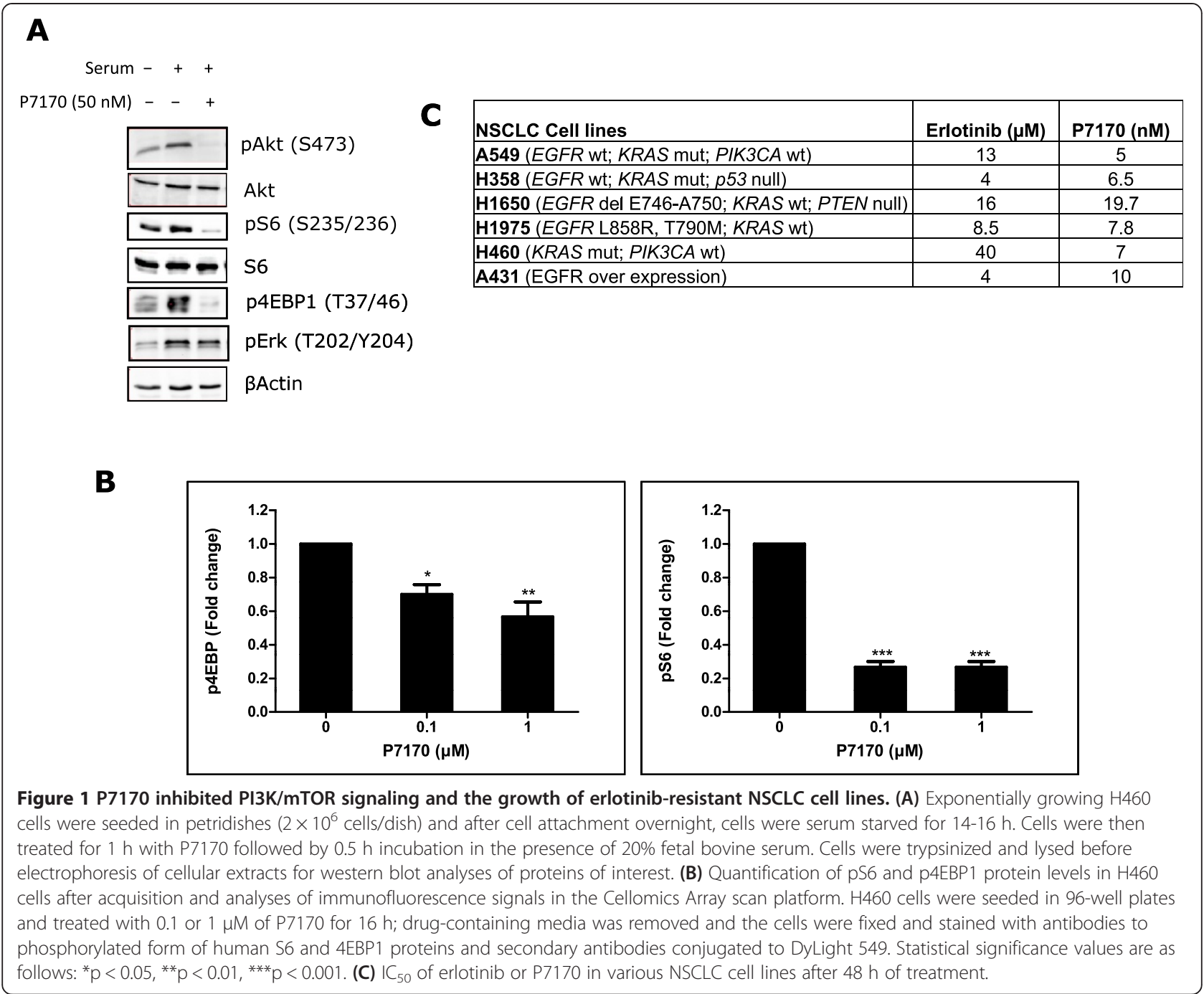

viability with $22 \%$ cells in late apoptosis/necrosis, and $11 \%$ cells in early apoptosis indicating the onset of cell death (Figure 2B; Additional file 3: Figure S3). The onset of apoptosis correlated with cell growth inhibition at similar concentrations $(100-300 \mathrm{nM})$ and at the same incubation time of 24 h (Figure 2A). To ascertain whether apoptotic response by P7170 involves DNA damage or elicited DNA damage-repair response, PARP cleavage, a widely used marker for measuring DNA-damage repair response was examined. In a separate experiment, treatment of H460 cells with an increasing concentration of P7170 was found to induce PARP cleavage (Figure 2C).

Since P7170 also inhibited JAK2 kinase activity $\left(\mathrm{IC}_{50}\right.$ : $39 \mathrm{nM}$, manuscript submitted), we evaluated STAT3 activation, a target downstream of JAK2 because similar to PI3K pathway, STAT-family members are activated upon phosphorylation (at different Serine/Tyrosine residues) by cytokines and growth factors. Using a cell based
STAT3-reporter assay, P7170 demonstrated a marked inhibition of transcriptional activation of STAT3 in HeLa cells $(\mathrm{p}<0.01)$ with minimal $(18 \%)$ cytotoxicity $\left(\mathrm{IC}_{50}\right.$ : 4.7nM, Figure 2D). Also, in an immunofluorescence assay in A549 NSCLC cells, there was a prominent decrease in the nuclear staining for phosphorylated STAT3 (Y705) after treatment with 0.1-1 $\mu \mathrm{M}$ P7170 (Figure 2E).

\section{In vivo anti-tumor efficacy of $\mathrm{P} 7170$ in mice bearing NSCLC xenografts}

In order to understand the antitumor efficacy of P7170 in erlotinib-sensitive and insensitive in vivo models, subcutaneous xenografts of NSCLC, using H1975, H1650, or H460 cell lines were established. Although H1650 and H1975 cell lines are equally responsive to erlotinib in vitro, literature $[24,25]$ suggests that $\mathrm{H} 1975$ xenografts are erlotinib-resistant. Treatment with P7170 resulted in a significant growth inhibition (70\% TGI, p < 0.001, 
Table 1 P7170 inhibits the growth of NSCLC patient-derived cancer cells

\begin{tabular}{|c|c|c|c|c|c|c|}
\hline Tumor designation & Model \# & Histology & Kras & PIK3CA & PTEN & IC50 (nM) \\
\hline LXFA & 1012 & adenocarcinoma & wt & wt & wt & 45 \\
\hline LXFA & 1584 & adenocarcinoma & NA & NA & NA & 2 \\
\hline LXFA & 586 & adenocarcinoma & wt & wt & wt & 9 \\
\hline LXFA & 629 & adenocarcinoma & wt & wt & wt & 5.5 \\
\hline LXFA & 677 & adenocarcinoma & wt & wt & wt & 300 \\
\hline LXFA & 737 & adenocarcinoma & wt & wt & wt & 300 \\
\hline LXFA & 749 & adenocarcinoma & wt & wt & wt & 17 \\
\hline LXFE & 1422 & Squamous cell carcinoma & wt & wt & wt & 8.5 \\
\hline LXFE & 470 & Squamous cell carcinoma & wt & E545K heterozygous & wt & 50 \\
\hline LXFE & 646 & Squamous cell carcinoma & wt & wt & wt & 100 \\
\hline LXFL & 1674 & Large cell & G12C homozygous & wt & wt & 30 \\
\hline LXFL & 430 & Large cell & wt & wt & wt & 3 \\
\hline LXFL & 529 & Large cell & wt & wt & wt & 50 \\
\hline
\end{tabular}

Various patient tumor xenograft-derived NSCLC cells treated with P7170 at log concentrations (range: $0.01 \mathrm{nM}-1 \mu \mathrm{M}$ ) followed by growth in soft-agar to evaluate colony formation. Description of patient's tumor histology sub-type, mutation status, and $\mathrm{IC}_{50}$ of P7170 in these tumor xenograft-derived cells by soft-agar colony formation is shown.

Table 2) of xenograft derived from H1650 erlotinibsensitive cells [EGFR del E748-A750 (activating mutation); KRAS mutant; PIK3CA wild type] at $5 \mathrm{mg} / \mathrm{kg}$, a dose much lower than its MTD. However, the same dose of P7170 was not very effective in mice bearing erlotinibinsensitive H1975 [EGFR T790M, L858R; KRAS wild type; PIK3CA wild type] xenografts, but treatment with a15 $\mathrm{mg} / \mathrm{kg}$ dose resulted in a significant tumor growth inhibition (92\% TGI, $\mathrm{p}<0.001$, Table 2). Interestingly, P7170 was efficacious (88\% TGI at $20 \mathrm{mg} / \mathrm{kg}$; 66\% TGI at $10 \mathrm{mg} / \mathrm{kg}$ with $\mathrm{p}<0.001$, Table 2 and Figure 3A) in another model of erlotinib -insensitive H460 (EGFR wild type; KRAS mutant; PIK3CA mutant) xenografted animals. P7170 administration was well tolerated at doses up to $20 \mathrm{mg}$ in different xenograft models (Additional file 4: Figure S4). These results provide evidence for the efficacy of P7170 in erlotinib-sensitive, and -insensitive NSCLC irrespective of known genetic mutations in these cells.

\section{Pharmacokinetic-pharmacodynamic correlation of P7170 in human H460 NSCLC xenograft model}

H460 xenograft model was chosen for this study. Tumor bearing mice were treated with different doses of P7170. Administration of P7170 at a $20 \mathrm{mg} / \mathrm{kg}$ dose resulted in $88 \%$ tumor growth inhibition (Figure $3 \mathrm{~A}$ ) confirming the results of a previous experiment (Table 2). Tumor growth inhibition with 5 and $10 \mathrm{mg} / \mathrm{kg}$ doses was significant compared to the vehicle $(\sim 53$ and $66 \%$ respectively, $\mathrm{p}<0.05)$ but did not differ much between the doses. In the efficacy study (Figure 3A); plasma and tumor samples collected at $1,4,8$, or $24 \mathrm{~h}$ post P7170-last dose were analyzed to determine the concentrations of P7170 by LC-MS. The results of this experiment indicate a dose dependent increase in P7170 concentrations in the tumors based on area under the curve (AUC) (*p $<0.05$ between two doses for plasma or tumor P7170 concentrations independently; ${ }^{\mathrm{S}} \mathrm{p}<0.05$ is the significance when concentrations of P7170 in the plasma and tumor were compared; Figure 3B). Also, P7170 concentrations were 2.7-fold higher in tumor versus plasma in $20 \mathrm{mg} / \mathrm{kg}$ group.

In a separate PK-PD study, $\mathrm{H} 460$ xenograft-bearing mice were treated with P7170 $(1,5,10$, or $20 \mathrm{mg} / \mathrm{kg} /$ day $)$ consecutively for 3 days. Plasma and tumor samples were collected at $1,4,8$, and $24 \mathrm{~h}$ after the administration of the last dose for PK-PD-analyses. Based on the time to achieve Cmax, plasma and tumor concentrations of P7170 were pooled from two time points ( 1 and $4 \mathrm{~h}$ ) in each group (Figure 3B). Tumor to plasma concentrations revealed a preferential accumulation of $\mathrm{P} 7170$ in the tumor than plasma in a dose-dependent manner ( 3 - 11-fold) (Figure 3B). To ascertain the pharmacodynamic effect of P7170 in tumor xenografts, western blotting of key proteins in the PI3K-Akt-mTOR pathway in tissue extracts was performed, and the representative protein blots derived from the samples collected during 1-8 $\mathrm{h}$ post P7170-last-dose are shown (Figure 3C). AKT phosphorylation (S473) the direct substrate of mTORC2 was found to be strongly inhibited in response to 10 or $20 \mathrm{mg} / \mathrm{kg}$ treatment. Also, the phosphorylation of ribosomal S6 (S235/236) and 4EBP1 (T37/46), targets downstream of mTOR were inhibited by $5-20 \mathrm{mg} / \mathrm{kg}$ doses (Figure $3 \mathrm{C}$ ). For the PK-PD-analyses, the normalized individual protein band intensities (pAKT, pS6, or p4EBP1) were plotted against P7170 concentrations in respective tumor samples. PK-PD analyses were carried out based on Inhibitory $\mathrm{E}_{\max }$ models (Additional file 5: Table S1) using 


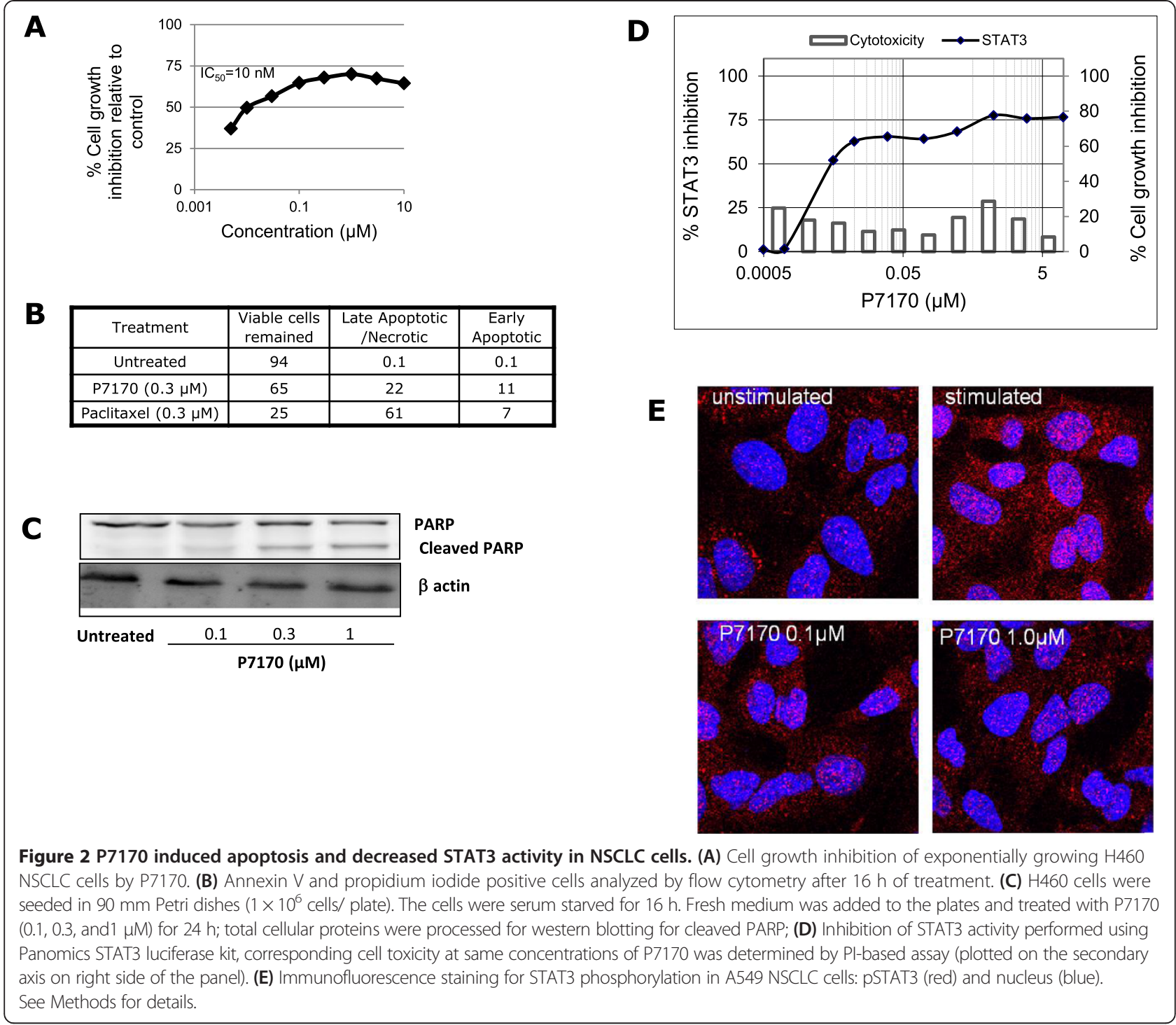

Table 2 P7170 decreased growth of NSCLC cell line-derived tumor xenografts

\begin{tabular}{cccc}
\hline \multicolumn{4}{l}{ Percent tumor growth inhibition in NSCLC-derived xenografts } \\
\hline P7170 $($ p.o., $Q$ QD) & $\mathbf{H 1 6 5 0}$ & $\mathbf{H 1 9 7 5}$ & $\mathbf{H 4 6 0}$ \\
\hline $5 \mathrm{mg} / \mathrm{kg}$ & $70 \%(\mathrm{p}<0.001)$ & $45 \%(\mathrm{p}<0.01)$ & $53 \%(\mathrm{p}<0.001)$ \\
$15 \mathrm{mg} / \mathrm{kg}$ & & $92 \%(\mathrm{p}<0.001)$ & $66 \%(\mathrm{p}<0.001)$ \\
$20 \mathrm{mg} / \mathrm{kg}$ & & & $88 \%(\mathrm{p}<0.0001)$ \\
$\begin{array}{c}\text { Duration of } \\
\text { treatment }\end{array}$ & 15 days & 13 days & 11 days
\end{tabular}

Tumor volume at the beginning of treatment $\sim 100 \mathrm{~mm} 3$

Nude mice bearing xenografts of human NSCLC cell lines H1650, H1975, or $\mathrm{H} 460$ were treated with $\mathrm{P} 7170$ at indicated doses for $10-15$ days (p.o., QD). All mice maintained body weight with a loss not more than $10 \%$.
Phoenix WinNonlin software (version 6.1) to evaluate the correlation between the level of tumor biomarkers (pAKT, pS6, and p4EBP1) and plasma and tumor concentrations of P7170. A trend showing a decrease in pS6 levels with increasing tumor and plasma P7170 on day 3, indicates target pathway engagement (Figure 3D). No correlations were observed for pAKT and p4EBP1 (Additional file 6: Figure S5). Additional details for PD model and parameter estimates are presented in Additional file 5: Table S1.

\section{Statistics}

Results are presented as mean \pm standard deviation. Statistical significance was determined using the two-way ANOVA with Turkey's post hoc test. Data with $\mathrm{p}<0.05$ were considered significant. Statistical analysis was done using GraphPad Prism, version 5.0c. 


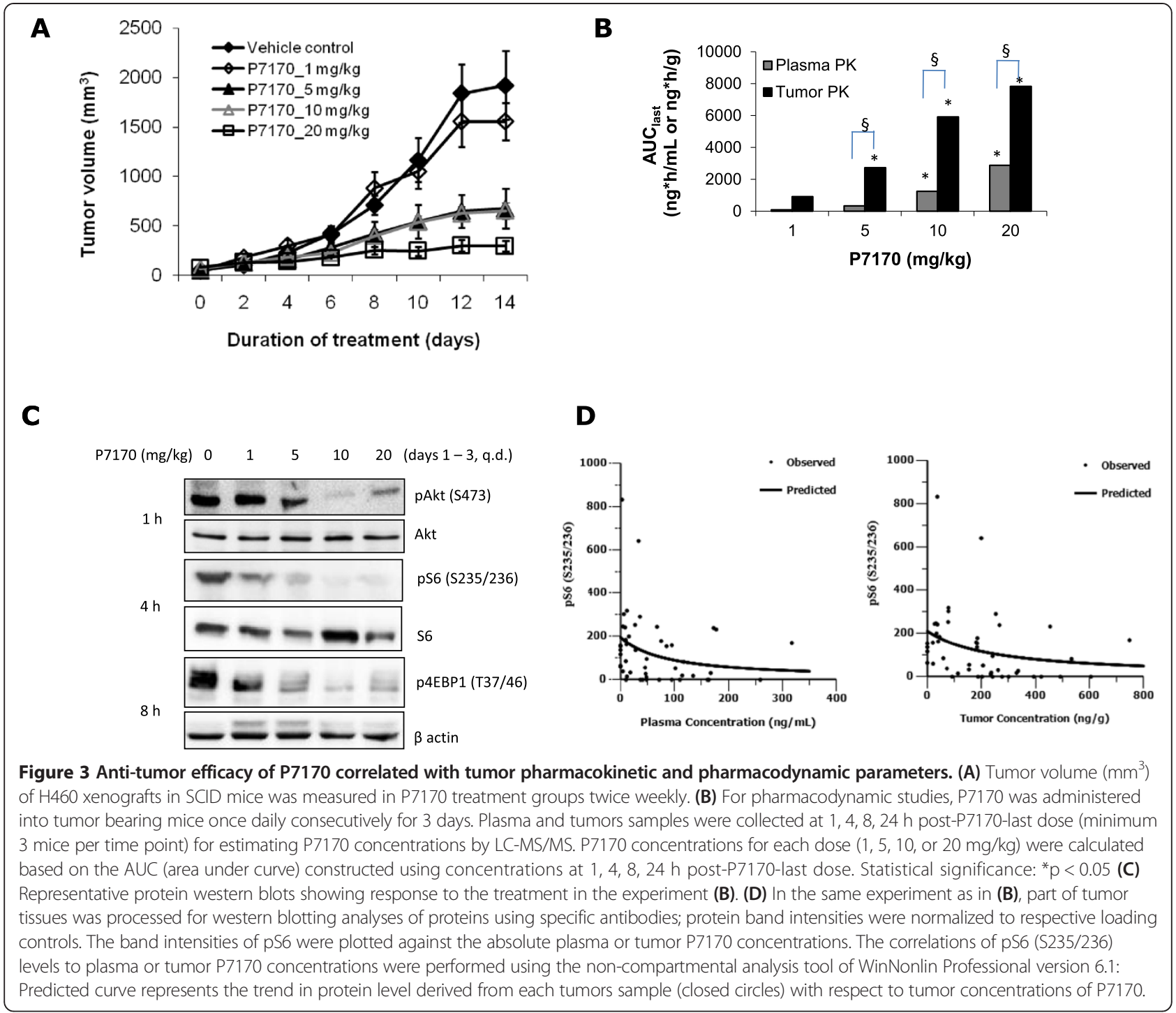

\section{Discussion}

In cancer, majority of growth factor receptor protein tyrosine kinases such as EGFR, HER2/3, FGFR, PDGFR, IGFR were found to be hyper activated. The important downstream pathways that are instrumental in regulating cell survival include, PI3K/mTOR and RAS-ERK. Many PI3K-AKT inhibitors have not produced the expected responses in patients with advanced cancers at tolerated doses. Benefit from AKT inhibition is limited due to mTORC2-mediated reactivation of PI3K-AKT signaling [23]. As mTOR is frequently hyper activated in human tumors and because the activity of both mTORC1 and mTORC2 complexes is essential for growth of a subset of tumors we aimed to develop an inhibitor for both these complexes.

We describe here the antitumor efficacy of an agent P7170 attributed to inhibition of mTORC1/mTORC2/ ALK1, and JAK-STAT3 signaling in NSCLC. We show that treatment with $\mathrm{P} 7170$ results in a marked reduction in the survival of NSCLC cells with different mutations in EGFR, KRAS, PIK3CA, or PTEN and inhibition of tumor growth in vivo. Supported by its pharmacodynamic effects (inhibition of phosphorylation of mTOR pathway proteins such as AKT, ribosomal S6, and 4EBP1) development of P7170 provides an attractive opportunity as a treatment option for NSCLC.

Consistent with reports suggesting a critical importance of mTOR pathway for the clonogenic cell growth [26], we found P7170 to inhibit colony formation of various patient-derived NSCLC cell lines in the soft-agar assay. Inhibition of mTOR signaling contributed to increased cellular apoptosis (PARP cleavage and Annexin V positive cells) with concomitant decrease in the growth of H460 cells. The decreased cell growth by P7170 could have resulted in inability of cells to colonize. An $\mathrm{IC}_{50}$ concentration of P7170 (10 nM) where $50 \%$ of cells did 
not undergo apoptosis indicated other mechanisms may be involved mediating cell death. To delineate this, we found studies reporting a persistent activation of STAT3 (pSTAT3) in nearly $50 \%$ of lung adenocarcinomas [27]. It is known that JAK2 directly regulate STAT3 activation [28], and since P7170 is known to have activity against the JAK2 kinase, it was hypothesized that P7170 may inhibit STAT3 activation. As expected, P7170 inhibited STAT3 activity in a luciferase expression system in HeLa cells. In an immunofluorescence assay, P7170 has also inhibited STAT3 phosphorylation (Y705) in situ in A549 NSCLC cells. In understanding the functional effect of these results, a study showed that inhibition of STAT3 was responsible for NSCLC tumor growth suppression [29] suggesting that inhibition of JAK2-STAT3 could be a mechanism for cellular apoptosis in P7170 treated cells.

We have demonstrated the in vivo antitumor efficacy of P7170 in xenograft models of different erlotinib-sensitive, and -resistant NSCLC cell lines at tolerated doses, and particularly, in xenografts derived from EGFR T790M, L858R erlotinib-resistant cells. The results of the present PK/PD study show mTORC1 and mTORC2 target engagement with a negative correlation between tumor volume and plasma/tumor P7170 concentrations. With the patient treatment in perspective, second generation EGFR TKI or combination with mTOR inhibitor for NSCLC patients with EGFR T790M mutation [30] could potentially become options. Although therapeutic options for NSCLC patients with KRAS mutation is lacking, new approaches in the clinical testing such as dual MEK and mTOR inhibition or cytotoxic drugs [31] are being evaluated. Therefore, targeting of mTOR cell survival/ growth pathways in subjects with erlotinib -sensitive and -insensitive NSCLC might be beneficial. In summary, P7170 showed a target engagement, resulted in tumor cell killing leading to tumor growth inhibition in vivo.

\section{Conclusions}

Taken together, our results demonstrate that P7170 has NSCLC cell killing activity via inhibition of mTORC1/ mTORC2 and JAK2-STAT3 signaling. This activity resulted in tumor growth inhibition as a single agent in the in vivo xenograft models. Therefore, we propose that P7170 could produce benefit in patients with erlotinibsensitive, and -insensitive NSCLC.

\section{Methods}

\section{Cell lines and culture}

A549, H358, H1975, H1650, and H460 cell lines were purchased from ATCC and maintained in RPMI1640, supplemented with 10\% heat inactivated FBS (Gibco). STAT3 Reporter HeLa Stable Cell Line (stably transfected with Luciferase gene under the control of STAT3 promoter) was purchased from Panomics, USA and was maintained in DMEM supplemented with 10\% FBS under hygromycin B (Sigma H3274) selection condition. Experimental culture conditions for patient tumor derived cells are given below in methods.

\section{Cell growth inhibition assay Propidium iodide assay}

Exponentially growing cells were plated in 96-well plate $24 \mathrm{~h}$ before treatment with P7170. After $48 \mathrm{~h}$ of incubation plates were washed with $1 \times \mathrm{PBS}$ followed by addition of PI-containing PBS $(7 \mu \mathrm{g} / \mathrm{ml})$ and storage at $-80^{\circ} \mathrm{C}$. After thawing the plate PI fluorescence was measured in POLAR STAR OPTIMA (BMG Lab technologies). Cell Growth Inhibition was normalized to the controls.

\section{Soft-agar colony formation of patient tumor-derived xenograft cells}

P7170 was evaluated at log concentrations from $0.01 \mathrm{nM}$ to $1 \mu \mathrm{M}$ in a 14-day soft agar colony formation assay. The Patient tumor explants are passaged as subcutaneous xenograft in NMRI nu/nu mice. For the clonogenic assay, cells were isolated from tumor xenografts (also referred to as patient derived tumor xenografts, PDX) of 13 NSCLC patient specimens established in mice under sterile conditions followed by mechanical disaggregation and subsequent incubation with an enzyme cocktail [consisting of collagenase type IV $(41 \mathrm{U} / \mathrm{ml})$, DNase I $(125 \mathrm{U} / \mathrm{ml})$, hyaluronidase type III $(100 \mathrm{U} / \mathrm{ml})$ and dispase II $(1.0 \mathrm{U} / \mathrm{ml})$ in RPMI 1640 medium] at $37^{\circ} \mathrm{C}$ for 45 minutes. Cells were allowed to pass through sieves of $200 \mu \mathrm{m}$ and $50 \mu \mathrm{m}$ sterile nylon mesh and washed twice with sterile PBS buffer. The percentage of viable cells is determined in Neubauer Hemocytometer using trypan blue exclusion. The bottom layer consisted of $0.2 \mathrm{ml} /$ well Iscove's Modified Dulbecco's Medium (Invitrogen), supplemented with 20\% (v/v) fetal calf serum (Sigma), 0.01\% (w/v) gentamicin (Invitrogen) and $0.75 \%(\mathrm{w} / \mathrm{v})$ agar (BD Biosciences). Tumor cells were added to $0.2 \mathrm{ml}$ of the same culture medium supplemented with $0.4 \%(\mathrm{w} / \mathrm{v})$ agar and plated in 24-multiwell dishes onto the bottom layer. P7170 at desired concentration in $0.2 \mathrm{ml}$ culture medium was overlaid on the bottom layer. Every dish included six untreated control wells and drug treated groups in triplicate at 6 concentrations. Cultures were incubated at $37^{\circ} \mathrm{C}$ and $7.5 \% \mathrm{CO}_{2}$ in the humidified atmosphere for up to 20 days and monitored closely for colony growth using an inverted microscope. Within this period, in vitro tumor growth leads to the formation of colonies with diameter $>50 \mu \mathrm{m}$. At the time of maximum colony formation, counts were performed with an automated image analysis system (OMNICON 3600, Biosys $\mathrm{GmbH}) .24 \mathrm{~h}$ prior to evaluation, vital colonies are stained with a sterile aqueous solution of 2-(4-iodophenyl)-3-(4nitrophenyl)-5-phenyltetrazolium chloride $(1 \mathrm{mg} / \mathrm{ml}, 100$ 
$\mu \mathrm{l} /$ well). $\mathrm{IC}_{50}$ values were calculated by two point curve fit [(conc. Of inhibitor) versus response $(\% \mathrm{~T} / \mathrm{C})]$ using Oncotest in house database system) or nonlinear regression [log (conc. of inhibitor)] versus response (\% T/C) using Graph pad Prism 5 for windows, version 5.01, Graph pad software Inc. CA). For calculation of mean $\mathrm{IC}_{50}$ values the geometric mean is used. Results are presented as mean graph plots or heat maps (individual $\mathrm{IC}_{50}$ values relative to the geometric mean $\mathrm{IC}_{50}$ value) over all cell lines as tested.

\section{Immunoblotting}

Whole cell extracts from treated cell lines or xenografts were prepared using cell lysis buffer [a mixture of protease inhibitor cocktail (Sigma, Cat \#P8340) and phosphatase inhibitors (40 mM Beta-glycerol phosphate (Sigma, Cat \#G9422), 4 mM DTT (MP Biomedicals, Cat \#194821), $0.4 \mathrm{mM}$ NaF (Sigma Cat \#S1504), $0.4 \mathrm{mM}$ Sodiumorthovanadate (Sigma, Cat \#S6508)]. Total protein concentration from the soluble fraction was determined by Bradford's method. Equal amount of total protein was resolved on SDS-PAGE gels; protein bands were electrotransferred onto PVDF membrane. Antibodies for immunoblotting are from Cell Signaling Technology [pAKT (S473) (\#9271); AKT (\#9272); pS6 (S235/236) (\#2211); S6 (\#2217); p4EBp1 (T37/46) (\#9459); pERK (T202/Y204) (\#9101); ERK (\#4695)]; and from Sigma (Actin \#A2228). SuperSignal West Femto (Thermo Scientific Cat \#34096) was used for chemiluminescence detection and the signals were captured in the ChemiDoc XRS image system (BioRad). The protein western band intensities were calculated using NIH Image-J software.

\section{Immunofluorescence}

\section{pS6 and p4EBP1 staining}

H460 cells were seeded in 96-well Black/clear plates (Nunc) followed by treatment on the next day with P7170 for $1 \mathrm{~h}$. Cells were fixed with 3.7\% PFA in $1 \times$ PBS at RT for $20 \mathrm{~min}$, cell membranes permeabilized with $0.1 \%$ Triton X-100 for $90 \mathrm{sec}$, followed by blocking with $5 \%$ BSA (Sigma-Aldrich Cat \#A7030) (w/v) in $1 \times$ PBS for $2 \mathrm{~h}$ before immunostaining. Primary antibodies used were pS6 and p4EBP1 (Cell Signaling) at dilution (1:500) at RT for $1 \mathrm{~h}$. Secondary Goat Anti-Rabbit antibody IgG $(\mathrm{H}+\mathrm{L})$ DyLight 549 Thermo Scientific Cat \#35557) probed at 1:1000 dilution for $1 \mathrm{~h}$. Nuclei were stained with Hoechst 33342 (AnaSpec Inc. Cat \#83218). Plates were scanned on Cellomics Array Scan VTI HCS Reader.

\section{pSTAT3 staining}

Exponentially growing A549 cells were seeded on coverslips in a 24 well plate (Nunc) in complete growth media for 14-16 $\mathrm{h}$ followed by culture in no serum media for another 16-20 h. Serum starved cells were treated with P7170 $(0.1-1 \mu \mathrm{M})$ for $1 \mathrm{~h}$ followed by stimulation with
$30 \mathrm{ng} / \mathrm{ml}$ rhIL-6 (R\&D systems Cat. No. 206-IL) for $20 \mathrm{~min}$. Cells were washed with $1 \times \mathrm{PBS}$, fixed and permeabilized as described earlier. Primary antibodies used were pSTAT3 ${ }^{\left({ }^{\text {Y705) }}\right.}$ (Cell Signaling Cat \#9131) incubated (1:100 dilution) at RT for $1 \mathrm{~h}$. Secondary antibody and nuclear staining performed as earlier. Cell images were captured by confocal microscopy (Leica, LSM700) with ZEN2009 software.

\section{Annexin V - FITC staining and flow cytometry}

Exponentially growing $\mathrm{H} 460$ cells were seeded in 6 well plate, treated $16 \mathrm{~h}$ later with P7170 at $0.3 \mu \mathrm{M}$ for $24 \mathrm{~h}$. Cells were harvested by trypsinization and processed for FITC Annexin V staining as per manufacture's protocol (BD Pharmingen Cat \#556420). The samples were acquired by FACSCalibur flow cytometer and the signal intensities were analyzed using CellQuest Pro software (Becton Dickinson).

\section{STAT3 luciferase assay}

STAT3 Reporter HeLa cells were seeded $\left(2 \times 10^{4}\right.$ cells/well $)$ in a 96- well white plate (Nunclon Cat \#167008). After $16 \mathrm{~h}$, cells were treated for $1 \mathrm{~h}$ with P7170 followed by stimulation with $100 \mathrm{ng} / \mathrm{ml}$ Oncostatin M (Calbiochem Cat \#496260) for $7 \mathrm{~h}$. Cells were lysed in a buffer (a mixture of $125 \mathrm{mM}$ Tris phosphate buffer, $10 \mathrm{mM}$ EDTA, $10 \mathrm{mM}$ DTT, $50 \%$ glycerol, $5 \%$ Triton $\times 100$ ) before the addition of luciferin (Promega Cat \#E160E), ATP (Sigma Cat \#A2383), and coenzyme A (Sigma Cat \#C3019). The luminescence generated was measured using POLARstar OPTIMA (BMG Lab technologies). Cytotoxicity due to drug treatment (total $8 \mathrm{~h}$ ) was determined using propidium iodide.

\section{In vivo xenograft models of NSCLC cell lines and treatment}

Nude mice (male, $~ 6$ wks.) from Harlan Labs were housed in animal isolators (Harlan Inc.) with $12 \mathrm{~h}$ light dark cycle, $55-75 \%$ relative humidity at $22-25^{\circ} \mathrm{C}$ of room temperature, given access to autoclaved rodent diet (National Centre for Laboratory Animal Sciences, Hyderabad, India) and water ad libitum. Animals were acclimatized for a week before implanting subcutaneously with $5 \times 10^{6}$ NSCLC cells $(0.2 \mathrm{ml} / \mathrm{site}$ with $\mathrm{BD}$ matrigel $)$ in the right flank. When the mean xenograft size reached $\sim 100 \mathrm{~mm}^{3}$, mice were randomized into the study groups ( $n=9 /$ group). P7170 was suspended in $0.25 \%$ CMC $+0.1 \%$ Tween- 80 for administering via oral (p.o.) route. Animal body weight and physical signs were monitored throughout the experiment every day. The tumor size was measured with calipers 2-3 times/wk. and the tumor volumes were calculated using the following formula: (length $x$ width $)^{2} \times 0.5$. 


\section{Pharmacokinetic (PK) and Pharmacodynamic (PD) study PK analyses}

Plasma samples or tumor homogenates were processed to extract P7170 followed by determining P7170 concentrations using LC-MS/MS.

\section{Tumor homogenate preparation}

Tumor samples were diluted 4 times of its weight with homogenization solvent methanol: saline (75:25 v/v) and then homogenized to obtain tissue extracts until a uniform homogenate was obtained.

\section{Sample preparation}

An aliquot $(100 \mu \mathrm{L})$ of plasma or tumor homogenate was spiked individually with $10 \mu \mathrm{L}$ of internal standard (P6569, a compound structurally similar to P7170, $1.0 \mu \mathrm{g} / \mathrm{mL}$ ). The samples were vortexed for 10 seconds followed by addition of $1 \mathrm{~mL}$ ethyl acetate and further vortexed for $5 \mathrm{~min}$. The samples were then centrifuged at $10000 \mathrm{rpm}$ for 5 minutes at $4^{\circ} \mathrm{C}$. Supernatants $(800 \mu \mathrm{L})$ were transferred to relabeled glass tubes and its solvent portion was allowed to evaporate under nitrogen. The dried residues were reconstituted using $200 \mu \mathrm{L}$ acetonitrile: water (90:10 v/v) by vortex and centrifuged. The supernatants were analyzed for P7170 by a fit-for-purpose LC-MS/MS method. Pharmacokinetic analyses were carried out at each dose level using the non-compartmental analysis tool of Phoenix WinNonlin software (Version 6.1).

\section{LC-MS/MS analysis}

The chromatographic LC-MS/MS system consisted a Shimadzu LC pump with an API 4000 triple mass spectrometer (Applied Biosystems/MDS Sciex, Foster City, CA) fitted with a Turbolon- Spray interface. P7170 and P6569 (internal standard) were separated on a Thermo BDS Hypersil C18 column of $100 \times 4.6 \mathrm{~mm} \mathrm{I.D.} \mathrm{and}$ particle size of $5 \mu$. The mobile phase composed of two solvents: Solvent A, $5 \mathrm{mM}$ Ammonium formate in $0.1 \%$ formic acid and the Solvent B, Acetonitrile in a ratio of 20:80\% v/v, respectively. The isocratic HPLC condition was used for analysis. The samples were introduced into the HPLC column with a SIL-20 AC XR autosampler (Shimadzu) and an integrated HPLC pumping system (Shimadzu LC-20 AD XR) with $5 \mu \mathrm{L}$ injection volume at a flow rate of $0.8 \mathrm{~mL} / \mathrm{min}$ for a $3 \mathrm{~min}$ run time. The analytes were then eluted at RT 1.45 and $1.50 \mathrm{~min}$ for P7170 and P6569, respectively followed by MS detection. Electro-spray ionization in positive ion mode (ESI+) was used for ionization and multiple reaction monitor (MRM) mode was chosen for detection. The precursorproduct ions pairs were $\mathrm{m} / \mathrm{z} 528.0 \rightarrow 461.4$ (for P7170), and $\mathrm{m} / \mathrm{z} 504.3 \rightarrow 437.2$ (for internal standard, P6569). The optimized acquisition parameters were: Temperature set at $400^{\circ} \mathrm{C}$; Curtain gas (CUR), 30 psi (99.99\% Nitrogen);
Nebulizer Gas (Gas 1), 60 psi (99.99\% Nitrogen); Heater Gas (Gas 2), 50 psi (99.99\% Nitrogen); Collision-Activated Dissociation (CAD) Gas: 10 v; Ion Spray Voltage (IS), $5500 \mathrm{v}$.

The unknown plasma and tumor concentrations of P7170 (unbound and plasma protein bound) were calculated from the calibration standards at 0 to $15000 \mathrm{ng} / \mathrm{mL}$ by spiking $10 \times$ standards in blank plasma and tumor homogenates collected from untreated nude mice using linear regression according to the following equation:

$$
y=a x+b
$$

Where,

$y=$ Peak area ratio of analyte: internal standard

$\mathrm{b}=$ Intercept of the corresponding standard curve

$\mathrm{a}=$ Slope of the standard curve

$\mathrm{x}=$ Concentration of analyte $(\mathrm{ng} / \mathrm{mL})$

Pharmacokinetic analysis was carried out at each dose level using the non-compartmental analysis tool of WinNonlin Professional version 6.1. Pharmacokinetic parameters were determined from mean plasma and tumor concentrations thus obtained at each time point by noncompartmental analysis using Phoenix WinNonlin Professional version 6.1. Concentrations below limit of quantification (LLOQ $=0.5 \mathrm{ng} / \mathrm{mL}$ ) were considered as zero for PK analysis. Nominal time points were used for PK analysis.

\section{PK-PD analyses}

PD analysis was performed to derive a correlation between tumor marker levels (pS6, pAKT and p4EBP1) and the corresponding plasma and tumor P7170 concentrations after dosing the tumor-bearing mice with P7170 once daily for 3 days. Plasma and tumors samples were collected at 1, 4, 8, $24 \mathrm{~h}$ post-P7170-last dose for estimating P7170 concentrations by LC-MS/MS. P7170 tumor concentrations for each dose $(1,5,10$, or $20 \mathrm{mg} / \mathrm{kg})$ were calculated based on the AUC (area under curve) constructed using concentrations at $1,4,8,24$ h post-P7170-last dose. The normalized phosphoprotein western band intensities of AKT (S473), S6 (S235/236), and 4EBP1 (T37/46) as determined in tumor xenografts (in 1, 4, 8, $24 \mathrm{~h}$ post P7170-last dose) of different experimental arms were plotted against corresponding tumor xenograft P7170 concentration using the non-compartmental analysis tool using Phoenix WinNonlin Professional version 6.1. The analyses were performed using various inhibitory $E_{\max }$ models available in Phoenix WinNonlin software (version 6.1). The model with the lowest AIC (Akaike Information Criteria) value is selected as the best fit model. If two models had similar AIC values, then selection was made qualitatively by visual inspection of the model fit and \% CV of the parameter estimates. 


\section{Additional files}

Additional file 1: Figure S1. P7170 inhibited PI3K-mTOR signaling pS6 (S235/236) and p4EBP1 (T37/46) protein levels were determined by immunofluorescence staining in $\mathrm{H} 460$ cells. $\mathrm{H460}$ cells were seeded in 96-well plates (black and transparent bottom) before treatment with 0.1 or $1 \mu \mathrm{M}$ of P7170 for $1 \mathrm{~h}$; drug containing media was removed and the cells were fixed and stained with antibodies to phosphorylated form of human S6 and 4EBP1 proteins and secondary antibodies conjugated to DyLight 549, and signals acquired and analyzed in Cellomics high content array scan reader.

Additional file 2: Figure S2. P7170 inhibits the colony formation of tumor cells isolated from Non Small Cell Lung Cancer patients. Dose response curves for various patient tumor xenograft-derived NSCLC cells treated with P7170 in a soft-agar colony formation assay.

Additional file 3: Figure S3. Cellular apoptotic analysis after P7170 treatment. In the flow cytometry analysis gating was set using untreated cells (A); Increased cellular apoptosis and necrosis after P7170 treatment (B) or Paclitaxel treatment (C).

Additional file 4: Figure S4. Body weight changes of nude mice bearing NSCLC cell line-derived xenografts treated with P7170. (A) Percent body weight changes in the H1650 NSCLC cell-derived xenograft treated with P7170 (see Table 2); (B) Percent body weight changes in the H1975 NSCLC cell-derived xenograft treated with P7170 (see Table 2); Percent body weight changes in the H460 NSCLC cell-derived xenograft treated with P7170 (see Figure 3A).

Additional file 5: Table S1. Summary of PK/PD study. Correlation analysis of tumor volume to P7170 concentration. E0 represents the level of biomarker in plasma and tumor at baseline i.e. when the concentration of drug in plasma and tumor is 0 (zero). I $C_{50}$ represents the concentration of drug in plasma and tumor required to produce $50 \%$ of the maximal inhibition.

Additional file 6: Figure S5. Pharmacodynamic correlation of pAKT (S473) and p4EBP1 (T37/46) with tumor P7170 concentrations. Based on the study described in Figure 3, pharmacodynamic correlations of tumor PAKT (\$473) and p4EBP1 (T37/46) levels to the plasma and tumor concentrations of P7170 were performed. The correlation plots calculated using the mode (Additional file 5: Table S1): Correlation of tumor pAKT levels with P7170 concentrations in plasma (A) and tumor (B); and correlation of tumor p4EBP1 levels with P7170 concentrations in plasma (C) and tumor (D).

\section{Abbreviations}

NSCLC: Non small cell lung cancer; mTOR: Mammalian target of Rapamycin; mTORC1: Mammalian target of Rapamycin complex 1; mTORC2: Mammalian target of Rapamycin Complex 2; EGFR: Epidermal growth factor receptor; TKI: Tyrosine kinase inhibitor; PI3K: Phosphoinositide 3-kinase; KRAS: Kirsten rat sarcoma virus; PK: Pharmacokinetics; PD: Pharmacodynamics; JAK2: Janus kinase 2; STAT3: Signal transducer and activator of transcription 3; TGI: Tumor Growth Inhibition.

\section{Competing interests}

The authors declare that they have no competing interests.

\section{Authors' contributions}

AJ carried out protein western blotting, cell growth inhibition, STAT3 reporter, immunofluorescence assays, and pharmacodynamic studies. MV performed mouse tumor xenograft and pharmacodynamic studies. VS and PP carried out experiments in mouse tumor xenograft models. JB set up JAK2 kinase assay. DB participated in general experimental planning. SC carried out kinase assays, flow cytometry, and protein western blotting experiments. AS carried out immunofluorescence experiments. VL performed cell growth inhibition assays in NSCLC cell lines. PT and AD performed pharmacokinetic experiments and analysis. RS and TA carried out PK-PD correlations. VD, BS, and SK involved in the design and synthesis of P7170. SS contributed in the study concept. W drafted the work and prepared the manuscript to be published. VA conceived the studies and design of most of the studies. All authors read and approved the final manuscript.

\section{Acknowledgement}

Colony forming assays were performed at Oncotest, Germany.
Received: 9 June 2014 Accepted: 24 November 2014

Published: 2 December 2014

\section{References}

1. Morace C, Spadaro A, Cucunato M, Tortorella V, Consolo P, Luigiano C, Stabile G, Bonfiglio C, Bellerone R, Fortiguerra A, Alibrandi A, Crino S, Carducci A, Resta ML, Ferrau O, Freni MA: High serum resistin in chronic viral hepatitis is not a marker of metabolic disorder. Hepatogastroenterology 2010, 57:1215-1219.

2. Pao W, Girard N: New driver mutations in non-small-cell lung cancer. Lancet Oncol 2011, 12:175-180.

3. Stella GM, Luisetti M, Inghilleri S, Cemmi F, Scabini R, Zorzetto M, Pozzi E: Targeting EGFR in non-small-cell lung cancer: lessons, experiences, strategies. Respir Med 2012, 106:173-183.

4. Johnson JL, Pillai S, Chellappan SP: Genetic and biochemical alterations in non-small cell lung cancer. Biochem Res Int 2012, 2012:940405.

5. van Zandwijk N, Mathy A, Boerrigter L, Ruijter $H$, Tielen I, de Jong D, Baas P, Burgers S, Nederlof P: EGFR and KRAS mutations as criteria for treatment with tyrosine kinase inhibitors: retro- and prospective observations in non-small-cell lung cancer. Ann Oncol 2007, 18:99-103.

6. Mok TS, Wu YL, Thongprasert S, Yang CH, Chu DT, Saijo N, Sunpaweravong P, Han B, Margono B, Ichinose Y, Nishiwaki Y, Ohe Y, Yang JJ,

Chewaskulyong B, Jiang H, Duffield EL, Watkins CL, Armour AA, Fukuoka M: Gefitinib or carboplatin-paclitaxel in pulmonary adenocarcinoma. N Engl J Med 2009, 361:947-957.

7. Tapia C, Savic S, Bihl M, Rufle A, Zlobec I, Terracciano L, Bubendorf L: [EGFR mutation analysis in non-small-cell lung cancer : experience from routine diagnostics]. Pathologe 2009, 30:384-392.

8. Boch C, Kollmeier J, Roth A, Stephan-Falkenau S, Misch D, Gruning W, Bauer $\Pi$, Mairinger T: The frequency of EGFR and KRAS mutations in non-small cell lung cancer (NSCLC): routine screening data for central Europe from a cohort study. BMJ Open 2013, 3:1-6.

9. Douillard JY, Shepherd FA, Hirsh V, Mok T, Socinski MA, Gervais R, Liao ML, Bischoff H, Reck M, Sellers MV, Watkins CL, Speake G, Armour AA, Kim ES: Molecular predictors of outcome with gefitinib and docetaxel in previously treated non-small-cell lung cancer: data from the randomized phase III INTEREST trial. J Clin Oncol 2010, 28:744-752.

10. Zhou C, Wu YL, Chen G, Feng J, Liu XQ, Wang C, Zhang S, Wang J, Zhou S, Ren S, Lu S, Zhang L, Hu C, Hu C, Luo Y, Chen L, Ye M, Huang J, Zhi X, Zhang Y, Xiu Q, Ma J, Zhang L, You C: Erlotinib versus chemotherapy as first-line treatment for patients with advanced EGFR mutation-positive non-small-cell lung cancer (OPTIMAL, CTONG-0802): a multicentre, open-label, randomised, phase 3 study. Lancet Oncol 2011, 12:735-742.

11. Massarelli E, Varella-Garcia M, Tang X, Xavier AC, Ozburn NC, Liu DD, Bekele BN, Herbst RS, Wistuba II: KRAS mutation is an important predictor of resistance to therapy with epidermal growth factor receptor tyrosine kinase inhibitors in non-small-cell lung cancer. Clin Cancer Res 2007, 13:2890-2896.

12. Riely GJ, Marks J, Pao W: KRAS mutations in non-small cell lung cancer. Proc Am Thorac Soc 2009, 6:201-205.

13. Brognard J, Dennis PA: Variable apoptotic response of NSCLC cells to inhibition of the MEK/ERK pathway by small molecules or dominant negative mutants. Cell Death Differ 2002, 9:893-904.

14. Wan PT, Garnett MJ, Roe SM, Lee S, Niculescu-Duvaz D, Good VM, Jones CM, Marshall CJ, Springer CJ, Barford D, Marais R, Cancer Genome P: Mechanism of activation of the RAF-ERK signaling pathway by oncogenic mutations of B-RAF. Cell 2004, 116:855-867.

15. Brognard J, Clark AS, Ni Y, Dennis PA: Akt/protein kinase B is constitutively active in non-small cell lung cancer cells and promotes cellular survival and resistance to chemotherapy and radiation. Cancer Res 2001, 61:3986-3997.

16. Engelman JA, Janne PA, Mermel C, Pearlberg J, Mukohara T, Fleet C, Cichowski K, Johnson BE, Cantley LC: ErbB-3 mediates phosphoinositide 3-kinase activity in gefitinib-sensitive non-small cell lung cancer cell lines. Proc Natl Acad Sci U S A 2005, 102:3788-3793.

17. Guix M, Faber AC, Wang SE, Olivares MG, Song Y, Qu S, Rinehart C, Seidel B, Yee D, Arteaga CL, Engelman JA: Acquired resistance to EGFR tyrosine kinase inhibitors in cancer cells is mediated by loss of IGF-binding proteins. J Clin Invest 2008, 118:2609-2619.

18. Yamamoto H, Shigematsu H, Nomura M, Lockwood WW, Sato M, Okumura N, Soh J, Suzuki M, Wistuba II, Fong KM, Lee H, Toyooka S, Date H, Lam WL, 
Minna JD, Gazdar AF: PIK3CA mutations and copy number gains in human lung cancers. Cancer Res 2008, 68:6913-6921.

19. Trigka EA, Levidou G, Saetta AA, Chatziandreou I, Tomos P, Thalassinos N, Anastasiou N, Spartalis E, Kavantzas N, Patsouris E, Korkolopoulou P: A detailed immunohistochemical analysis of the PI3K/AKT/mTOR pathway in lung cancer: correlation with PIK3CA, AKT1, K-RAS or PTEN mutational status and clinicopathological features. Oncol Rep 2013, 30:623-636.

20. Han SW, Kim TY, Jeon YK, Hwang PG, Im SA, Lee KH, Kim JH, Kim DW, Heo DS, Kim NK, Chung DH, Bang YJ: Optimization of patient selection for gefitinib in non-small cell lung cancer by combined analysis of epidermal growth factor receptor mutation, K-ras mutation, and Akt phosphorylation. Clin Cancer Res 2006, 12:2538-2544.

21. Engelman JA, Chen L, Tan X, Crosby K, Guimaraes AR, Upadhyay R, Maira M, McNamara K, Perera SA, Song Y, Chirieac LR, Kaur R, Lightbown A, Simendinger J, Li T, Padera RF, Garcia-Echeverria C, Weissleder R, Mahmood U, Cantley LC, Wong KK: Effective use of PI3K and MEK inhibitors to treat mutant Kras G12D and PIK3CA H1047R murine lung cancers. Nat Med 2008, 14:1351-1356.

22. Watanabe R, Wei L, Huang J: mTOR signaling, function, novel inhibitors, and therapeutic targets. J Nucl Med 2011, 52:497-500.

23. Sarbassov DD, Guertin DA, Ali SM, Sabatini DM: Phosphorylation and regulation of Akt/PKB by the rictor-mTOR complex. Science 2005, 307:1098-1101.

24. Suzuki T, Fujii A, Ohya J, Nakamura H, Fujita F, Koike M, Fujita M: Antitumor activity of a dual epidermal growth factor receptor and ErbB2 kinase inhibitor MP-412 (AV-412) in mouse xenograft models. Cancer Sci 2009, 100:1526-1531.

25. Iwai T, Moriya Y, Shirane M, Fujimoto-Ouchi K, Mori K: Continuous inhibition of epidermal growth factor receptor phosphorylation by erlotinib enhances antitumor activity of chemotherapy in erlotinib-resistant tumor xenografts. Oncol Rep 2012, 27:923-928.

26. Liu X, Powlas J, Shi Y, Oleksijew AX, Shoemaker AR, De Jong R, Oltersdorf T, Giranda VL, Luo Y: Rapamycin inhibits Akt-mediated oncogenic transformation and tumor growth. Anticancer Res 2004, 24:2697-2704.

27. Gao SP, Mark KG, Leslie K, Pao W, Motoi N, Gerald WL, Travis WD, Bornmann W, Veach D, Clarkson B, Bromberg JF: Mutations in the EGFR kinase domain mediate STAT3 activation via IL-6 production in human lung adenocarcinomas. J Clin Invest 2007, 117:3846-3856.

28. Hedvat M, Huszar D, Herrmann A, Gozgit JM, Schroeder A, Sheehy A, Buettner R, Proia D, Kowolik CM, Xin H, Armstrong B, Bebernitz G, Weng S, Wang L, Ye M, McEachern K, Chen H, Morosini D, Bell K, Alimzhanov M, loannidis S, McCoon P, Cao ZA, Yu H, Jove R, Zinda M: The JAK2 inhibitor AZD1480 potently blocks Stat3 signaling and oncogenesis in solid tumors. Cancer Cell 2009, 16:487-497.

29. Weerasinghe P, Garcia GE, Zhu Q, Yuan P, Feng L, Mao L, Jing N: Inhibition of Stat3 activation and tumor growth suppression of non-small cell lung cancer by G-quartet oligonucleotides. Int J Oncol 2007, 31:129-136.

30. Li D, Shimamura T, Ji H, Chen L, Haringsma HJ, McNamara K, Liang MC, Perera SA, Zaghlul S, Borgman CL, Kubo S, Takahashi M, Sun Y, Chirieac LR, Padera RF, Lindeman NI, Janne PA, Thomas RK, Meyerson ML, Eck MJ, Engelman JA, Shapiro Gl, Wong KK: Bronchial and peripheral murine lung carcinomas induced by T790M-L858R mutant EGFR respond to HKI-272 and rapamycin combination therapy. Cancer Cell 2007, 12:81-93.

31. Larsen JE, Cascone T, Gerber DE, Heymach JV, Minna JD: Targeted therapies for lung cancer: clinical experience and novel agents. Cancer $J$ 2011, 17:512-527.

doi:10.1186/1476-4598-13-259

Cite this article as: Venkatesha et al.: P7170, a novel inhibitor of mTORC1/mTORC2 and Activin receptor-like Kinase 1 (ALK1) inhibits the growth of non small cell lung cancer. Molecular Cancer 2014 13:259.

\section{Submit your next manuscript to BioMed Central and take full advantage of:}

- Convenient online submission

- Thorough peer review

- No space constraints or color figure charges

- Immediate publication on acceptance

- Inclusion in PubMed, CAS, Scopus and Google Scholar

- Research which is freely available for redistribution

Submit your manuscript at www.biomedcentral.com/submit
() Biomed Central 